\title{
Corrigendum: Frequency, Risk Factors, and Prognosis of Dehydration in Acute Stroke
}

\section{Elena Cortés-Vicente, Daniel Guisado-Alonso, Raquel Delgado-Mederos, Pol Camps-Renom, Luis Prats-Sánchez, Alejandro Martínez-Domeño and Joan Martí-Fàbregas *}

Department of Neurology, Hospital de la Santa Creu i Sant Pau, Biomedical Research Institute Sant Pau (IIB Sant Pau), Universitat Autònoma de Barcelona, Barcelona, Spain

Keywords: stroke, dehydration, urea, creatinine, prognosis, risk factors

\section{OPEN ACCESS}

Approved by:

Frontiers Editorial Office,

Frontiers Media SA, Switzerland

*Correspondence:

Joan MartíFàbregas

jmarti@santpau.cat

Specialty section:

This article was submitted to

Stroke,

a section of the journal

Frontiers in Neurology

Received: 10 June 2020

Accepted: 11 June 2020

Published: 17 July 2020

Citation:

Cortés-Vicente E, Guisado-Alonso D,

Delgado-Mederos $R$

Camps-Renom P, Prats-Sánchez L,

Martínez-Domeño $A$ and Martí-Fàbregas J (2020) Corrigendum:

Frequency, Risk Factors, and

Prognosis of Dehydration in Acute

Stroke. Front. Neurol. 11:717.

doi: 10.3389/fneur.2020.00717

\section{A Corrigendum on}

Frequency, Risk Factors, and Prognosis of Dehydration in Acute Stroke by Cortés-Vicente, E., Guisado-Alonso, D., Delgado-Mederos, R., Camps-Renom, P., Prats-Sánchez, L., Martínez-Domeño, A., et al. (2019). Front. Neurol. 10:305. doi: 10.3389/fneur.2019.00305

There is an error in the Funding statement. The correct number for Instituto de Salud Carlos III, RETICS (Redes Temáticas de Investigación Cooperativa en Salud) INVICTUS PLUS and FEDER is RD06/0019/0010. The corrected Funding statement appears below.

There is an error in the Funding statement. The correct Name for the Funder is Instituto de Salud Carlos III, RETICS (Redes Temáticas de Investigación Cooperativa en Salud) INVICTUS PLUS and FEDER. The corrected Funding statement appears below.

The authors apologize for this error and state that this does not change the scientific conclusions of the article in any way. The original article has been updated.

\section{FUNDING}

This work was supported by Instituto de Salud Carlos III, RETICS (Redes Temáticas de Investigación Cooperativa en Salud) INVICTUS PLUS RD06/0019/0010 and FEDER.

Copyright (c) 2020 Cortés-Vicente, Guisado-Alonso, Delgado-Mederos, Camps-Renom, Prats-Sánchez, Martínez-Domeño and Marti-Fàbregas. This is an open-access article distributed under the terms of the Creative Commons Attribution License (CC BY). The use, distribution or reproduction in other forums is permitted, provided the original author(s) and the copyright owner $(s)$ are credited and that the original publication in this journal is cited, in accordance with accepted academic practice. No use, distribution or reproduction is permitted which does not comply with these terms. 